\title{
SCHOOL-BASED ASSESSMENT IN ENGLISH LANGUAGE TEACHING: WEIGHING THE COW WILL NOT FATTEN IT
}

\section{Maryna Reyneke, North-West University}

Education systems of the $21^{\text {st }}$ century face the challenge of reflecting the needs of an extremely dynamic global society. Of paramount importance is students' aptitude for life-long learning; a quality that needs to be fostered and enhanced by sustainable assessment practices that focus on promoting learning instead of merely testing existing knowledge and skills. Within any contemporary educational system, school-based assessment (SBA) may be utilised to promote higher-order thinking skills. SBA is especially valuable in English language learning which involves the acquisition of a variety of linguistic and communication skills. In the South African system, however, SBA in English classrooms seems to amount to nothing more than regular summative testing, grading and record keeping of marks to satisfy bureaucracy and prepare candidates for high-stakes examinations.

Key words: School-based assessment; school-based assessment; English First Additional Language; learning-oriented assessment; $21^{\text {st }}$ century skills

\section{INTRODUCTION}

Following ground-breaking research by Black and Wiliam (1998) that demonstrated substantial gains in student learning when teachers focus on using assessment to improve learning, education systems around the world started reconsidering the role of assessment in curricula. The important paradigm shift, reflecting the response of $21^{\text {st }}$ century education systems to the needs of society, is the move from Assessment of Learning (AoL) to Assessment for Learning (AfL) (Brookhart, 2007; Darling-Hammond \& McCloskey, 2008). The former way of assessment is typically used in traditional tests and examinations aimed at summarising and reporting the overall achievement of learners (Vlachou, 2015: 101) while the purpose of the latter, also known as formative assessment, is to enhance both teaching and learning (Black, Harrison, Lee, Marshall \& Wiliam, 2003; Earl, 2013; Heritage, 2013; Wiliam, 2011). Learning-Oriented Assessment (LOA), another term used in contemporary academic discourse on assessment, also emphasises the learning aspects of assessment (Carless, 2007: 58).

One way of putting AfL into practice in examination-driven education systems, is to incorporate school-based assessment (SBA) into the formal assessment programme; an initiative already taken by a number of nations (Kellaghan \& Greaney, 2003; Stanley, MacCann, Gardner, Reynolds \& Wild, 2009; Qian, 2014).

This paper seeks to explore the implementation of SBA in English First Additional Language (EFAL) in the Further Education and Training (FET) phase (Grades 10-12) in public schools in South Africa and aims at addressing the issue of how SBA in EFAL could be more effectively focused on enhancing learning. This paper has three main strands. It starts off with a brief discussion of what summative and formative assessment entail, followed by a discussion of what is meant by LOA in language teaching and learning. Secondly, it focuses 
on SBA and concerns about its implementation. Finally, based on engagement with the relevant literature and analyses of relevant documents in the South African context, it looks at how the quality of SBA in EFAL in the FET phase may be improved.

\section{TYPES OF ASSESSMENT}

The literature draws a distinction between summative assessment (SA), also known as AoL, and formative assessment (FA), also referred to as AfL (Vlachou, 2015: 101). This distinction is not only based on the apparent difference in purpose and function of the assessment type, but also on the method and different time frames in which each is applied (Good, 2011; Harlen, 2012; Newton, 2007). In using the analogy of the cow, SA refers to weighing the cow while FA refers to feeding or fattening the cow.

As the term suggests, SA is a form of assessment largely concerned with the final summing up of educational work at the end of a study unit, programme, year's study, or educational experience (Isaacs, Zara, Herbert, Coombs \& Smith, 2013). It typically takes place in the form of tests and examinations, and is used as a basis for decision making on progress in a learning area, progress to a next grade or exit point possibilities. Results are of particular importance to parents who wish to know whether their child has shown progress, to tertiary institutions that process applications for further study, and to employers who wish to employ successful learners. Often statistics and data gathered from examination results are used to classify and rate schools in school effectiveness research programmes. As a formal technique SA is not only strongly established in most schools, but also entrenched in public examination systems.

Formative assessment, on the other hand, is less formal and less significant for people other than the learner, parent or teacher. Its sole purpose is to enhance teaching and learning. It fosters stronger connections between teaching, learning and assessment by focusing on evidence of learning and through an assessment process, it generates information which is used to adjust teaching and learning instruction to better meet learners' needs (Assessment Reform Group, 2002; Shepard, 2007; Wiliam, 2011). The roles of the teacher, learner and peer are highlighted in the assessment process to enhance ongoing learning and learner autonomy (TICAL, 2009). Using assessment to guide learners to better performance instead of judging their performance, and giving learners a more central role in assessment procedures as a means of achieving better learning, calls for a fundamental change in classroom culture; which means that AfL can never be seen as just another add-on to teaching and learning (Vlachou, 2015: 105). It should rather be seen as a long-term investment in the future for better teaching and learning.

Not all scholars, however, see AfL in the same way. Brookhart (2007) explains that the variation in definitions illustrates that the term has been evolving in parallel with learning theories and the needs of society. To some AfL is simply a fundamental part of good teaching which requires no extra work from the teacher. They see it as an informal and ad-hoc way of assessing learning and giving feedback during daily interaction in the classroom; others view formative assessment as mainly involving formal, structured tasks (Carless, 2007: 58). The implication of the latter view is that teachers have to plan for formative assessment, adding not only to their own workload but also to that of their learners who have to respond to formative assessment procedures. Neither teachers, nor learners might have time for that, especially when they find themselves in examination-driven contexts. 
Based on the different views of AfL and in an effort to avoid confusion about what assessment sets out to achieve, Carless (2007: 58) coined the term Learning-Oriented Assessment (LOA). He clarifies the term by explaining that learning comes first, both in the literal construction of the term and the principle of emphasising the learning aspect of assessment. Emphasis on the learning elements does however not imply the exclusion of the measurement ones (Carless, Joughin \& Mok, 2006). Building on the work of Boud (2000) who recognises the 'double duty' of assessment (assessment being about both grading and learning) Carless et al. (2006: 395) identify three main purposes of assessment: assessment as certification, assessment as learning and assessment to foster lifelong learning.

Learning is at the centre of both formal and informal assessments in LOA. Owing to its focus, Cambridge English Language Assessment (CELA) has adopted LOA in order to change the traditional relationship of assessment to learning (CELA, 2016). CELA, a world-renowned assessment body that has been providing English language assessments and qualifications for over 100 years, approaches LOA from an assessment specialist perspective, taking a systemic view where assessment operates on multiple levels and takes many forms. What is important is the belief that all levels of assessment (national examinations or school-based assessment) should contribute to both the effectiveness of learning and the reliable evaluation of outcomes. The Cambridge model for language assessment 'sets out to define a complementary relationship with teaching, based on a functional division between the dimensions of quantitative measurement (the domain of assessment expertise), and qualitative individualisation of approach to each learner (the domain of teaching expertise)' (CELA, 2016). In this model, teachers play a central role in creating an environment productive of learning, entirely complementary to the role of formal assessment in the form of either SBA or high-stakes examinations.

\section{School-based assessment versus standardised testing}

SBA is meant to integrate learning and teaching with assessment and to offer a more comprehensive appraisal of learners' performance, especially in language learning where all linguistic skills cannot be assessed through written examinations. Therefore it is inevitable that SBA is incorporated into public examinations in order to enhance the validity of the latter.

SBA calls for the active involvement of both teachers and learners in the classroom setting which is usually more relaxed and familiar to both parties. Teachers carry the responsibility of planning the assessment programme, finding and/or developing appropriate tasks and making final judgments while learners take part in peer- and self-assessment activities. Feedback generated by the assessment of both formative and summative tasks, is meant to lead to continuous improvement, boost learner confidence and motivation, and enhance autonomous learning (Davison, 2007: 38).

In reaction to the paradigm shift from AoL to AfL, SBA has become policy-supported practice in an increasing number of educational systems around the world including those of Australia, New Zealand, Canada, the United Kingdom, the United States of America, and more recently, Hong Kong (Hamp-Lyons, 2012). External, standardised testing, however, still dominates curricula in most localities (Darling-Hammond \& McCloskey, 2008: 271; Long, 2006: 2; Mak \& Lee, 2014: 74; McCollow, 2006: 10). The reason for such dominance is still the traditional goal of setting certain standards and evaluating learner performance in terms of 
those standards, pushing for national consistency in curriculum and assessment, and ensuring reliability and validity. In arguing against the use of external, high-stakes standardised testing in the United States, Kohn (2001: 350) says that standardised tests 'cannibalise the curriculum' and force schools to eliminate activities and leave out whole areas of the curriculum. Further, content is privileged over process, and knowledge over critical judgement; rote memory drills, basic comprehension, and multiple choice exercises are encouraged at the expense of activities that engage students' higher order thinking skills. In contrast to the promotion of 'shallow thinking' in test-driven systems (Kohn, 2001), European and Asian nations that have steeply improved student learning over the past two decades, have focused on utilising SBA to promote higher order thinking skills in equipping learners for life in the $21^{\text {st }}$ century (Darling-Hammond \& McCloskey, 2008: 264). In Finland and Sweden, where curricula and SBA have been aligned with high quality $21^{\text {st }}$ century learning outcomes, student learning has been successfully enhanced in such a way that these nations' extraordinary success in international examinations is often cited (Darling-Hammond \& McCloskey, 2008: 266).

\section{CONCERNS ABOUT THE IMPLEMENTATION OF SBA IN SOUTH AFRICA, WITH SPECIFIC REFERENCE TO EFAL}

There is clear evidence that countries such as Finland and Sweden, after intensive investments in teacher education, managed to successfully implement SBA on a large scale while countries such as Hong Kong and South Africa are confronted by serious implementation challenges (DBE, 2014; Qian, 2014). Common types of issues and problems are experienced with the SBA component of English in high-stakes national examinations in South Africa (Davison, 2007; Reyneke, Meyer \& Nel, 2010). The continuous focus on teaching and assessing high level linguistic and critical thinking skills is of particular importance in the study of English. Apart from EFAL being the subject with the highest number of registrations in the NCS examinations, English is the preferred medium of instruction for the majority of secondary school learners (DBE, 2014). Not only does English allow mobility in multilingual and multicultural worlds of life and work, but it also gives access to higher education and lifelong learning.

Brindley (1998) conducted a wide-ranging study on issues arising from the implementation of outcomes-based assessment and reporting in language learning programmes in the 1990s. Based on this study he identified three common types of issues and problems: political issues, to do with the purposes and intended use of the assessment; technical issues, primarily to do with validity and reliability; and practical issues, to do with the means by which the assessment was put into practice. Issues and concerns about the implementation of SBA in EFAL in the senior secondary phase in the South African system can be analysed by adapting Brindley's (1998) taxonomy of factors that influence assessment in language learning programmes. These issues and concerns can broadly be classified into three types: sociocultural, technical, and practical (Davison, 2007: 45).

\section{Sociocultural issues}

Brindley (1998: 62) observed that if the theoretical underpinnings of the (assessment) statements or the testing formats used are seen to be at variance with the strongly held views of powerful interest groups representing particular theoretical or pedagogical orientations, 
then their validity may well be publicly challenged, thus greatly reducing the likelihood of their adoption by practitioners.

In South Africa, learner performance in the National Senior Certificate (NSC) examination is a matter of public interest and has become a yardstick of the success of public schooling. Pass rates are what matter because pass rates are equated to educational standards. SBA is therefore strictly aligned with the end-of-year examinations in each level of the FET phase and with the high-stakes NSC examination at the end of the phase. The Curriculum and Assessment Policy Statement (CAPS) for EFAL in the FET phase clearly specifies what should be taught, which topics should be covered per subject, per grade, and per quarter of the school calendar year, and it provides guidelines on how informal, daily assessment and formal SBA must be carried out (DBE, 2011). The National Protocol of Assessment (DBE, 2012) stipulates how SBA marks should be recorded, moderated and reported. These processes are strictly monitored, more so in high performing schools that strive to maintain their good national ranking. The result is that teachers, who are held accountable for learner performance in national examinations, mechanically adhere to stipulations regarding SBA in the CAPS instead of creating worthwhile learning experiences, or generating assessment tasks aimed at the promotion of deep learning (DBE, 2014: 74). Clearly learning, which is at the centre of LOA in all forms of assessments, is neglected because the validity, reliability and authenticity of SBA is jeopardised by an exam-driven system (DBE, 2014).

\section{Technical issues}

At the technical level concerns with SBA revolve around the understanding and interpretation of traditional concepts such as reliability, validity, and authenticity (Brindley, 1998).

The validity of SBA lies in the fact that it is implemented in the actual classroom where assessment activities are embedded in the regular curriculum and by a teacher who is familiar with each learner's work. Unlike high-stakes examination papers which are once-off assessment opportunities based on only parts of the curriculum, SBA is concerned with the collection of multiple sources and types of evidence under naturalistic conditions over a lengthy period of time (Davison, 2007: 49). This means that the scope of validity is broadened with SBA (Rea-Dickins, 2006).

In the South-African educational system, however, teachers tend to prioritise the promotion role of SBA which results in a narrow assessment base (teaching and assessing to the test to 'train' learners for the final examination), the inflation of results to boost examination marks and consequently, ineffective learning and teaching (DBE, 2014: 14;122).

The suggested EFAL SBA programme, stipulated in the CAPS, reduces assessment to the testing of linguistic knowledge and skills through a series of summative tasks or tests that encourage rehearsed performances, most likely 'disembedded from the flow of teaching and learning' (Rea-Dickins, 2006: x). Further, it is evident that the evaluation criteria traditionally associated with psychometric testing such as reliability and validity have not been reinterpreted because of the remaining, strong focus on tests and examinations in the SBA programme. Three of the 10 tasks that constitute SBA in Grades 10 and 11 must be in the form of two tests that focus on Language in context (comprehension, summary, and language structures and conventions), and a mid-year examination with the latter comprising three papers: Language in context, Literature, and Writing. In Grade 12 the requirement is one test towards the end of Term 1 (Language in context) and two examinations (mid-year and the 
trial examination in September), comprising three papers: Language in context, Literature, and Writing. These are the three papers that learners of EFAL sit for at the end of each year in the FET phase. In the other seven SBA tasks learners practise creative and transactional writing, answer questions in the language paper that is set according to a fixed framework, or answer contextual questions in literature, all in preparation for the end-of-year examinations. While the National Protocol of Assessment (NPA) (DBE, 2012: 4) states that formal assessment tasks may take the form of projects, demonstrations, presentations, or performances in order to accommodate different learning styles, CAPS for EFAL in the FET phase makes no provision for such a variety of tasks. Instead the nature of SBA tasks seems to be determined by the foci of examination papers of poor quality (Kapp \& Arend, 2011; Du Plessis, 2014).

Three international benchmarking authorities, Cambridge International Examinations, the Scottish Qualifications Authority, and the Australian Board of Studies New South Wales were requested by a South African Task Team, appointed by the Minister of Basic Education in 2013, to analyse the 2010 EFAL papers written in the country's National Senior Certificate Examination (DBE, 2014).

The Cambridge International Examinations body found a heavy reliance on testing memorisation and recall, rather than critical thinking and analytical and evaluation skills. The Australian Board of Studies did not mince its words when it explained: 'The cognitive levels assessed in the examination questions are heavily weighted towards lower-order thinking skills... The grammatical activities themselves are meaningless and reflect a drill-and-practice approach to language learning, which does not support the need to develop learners' language for work and participation in the broader community...There is an insufficient focus on critical literacy and language analysis skills across papers' (DBE, 2014: 75-76). The Task Team reports that $40 \%$ of the NSC EFAL papers are on the lowest level of cognitive challenge because candidates seem unable to cope with questions requiring critical thinking skills, particularly extended responses (DBE, 2014: 74). These findings have serious implications for EFAL teachers who are the primary determinants of success in the classroom. They face the practical challenge of aligning SBA with high level $21^{\text {st }}$ century skills while ensuring learner success in public examinations.

\section{Practical issues}

Internationally, teachers are concerned about the following practical issues concerning the implementation of SBA: professional development in SBA, the need for appropriate assessment resources, the need for activities and techniques as models, lack of practical support at school level, lack of time to implement and give feedback on assessments, large classes, limited resources, and a heavy workload (Davison, 2007; Qian, 2010, Reyneke,et al., 2010; Stanley, et al., 2009).

In South Africa, submissions by teacher unions and quality assurance bodies such as the Independent Examination Board (IEB) and Umalusi (the council for quality assurance in general and further education) to the 2013 Ministerial Task Team suggest that teachers' inadequate professional knowledge is a major cause of the ineffective implementation of SBA, both as a teaching and learning tool and as an element in the final NSC mark (DBE, 2014: 120). Umalusi states that there are widespread tendencies in schools to design assessment tasks with low cognitive demand, to employ inappropriate marking methods, and to conduct poor moderation of assessments (DBE, 2014: 120). Furthermore EFAL teachers 
portray an inability to assess learners' innovative responses to open-ended questions, and to interpret assessment rubrics (DBE, 2014: 76). In an effort to counter this problem, the Task Team (DBE, 2014: 8) recommends that the implementation and moderation of SBA be thoroughly and regularly addressed during teacher development and training sessions to improve teachers' assessment literacy.

Teachers who are more assessment literate may be able to use the latitude that CAPS does allow them, within subject specifications, to devise learning and assessment programmes aimed at improving the quality of SBA in EFAL.

\section{IMPROVING THE QUALITY OF SBA IN EFAL IN THE FET PHASE (Feeding the cow)}

In terms of the literature surveyed previously and the evaluation of international benchmarking authorities, the quality of SBA in EFAL in the FET phase will be improved when teachers:

- $\quad$ are assessment literate;

- are prepared to focus on LOA;

- align teaching, learning and assessment with curriculum aims and objectives; and

- focus on high level cognitive and affective learner development.

Each of these will be discussed in turn to recommend initiatives that could change current SBA practice in EFAL teaching.

\section{Assessment literacy}

The paradigm shift in education from AoL to AfL drew international attention to teachers' assessment literacy (Mercurio, 2013; Wang, Wang \& Huang, 2008; Stiggins, 1995). As mentioned above, a high performing country such as Finland, attributes its educational gains to intensive investments in teacher education, particularly in assessment literacy (DarlingHammond \& McCloskey, 2008: 266). Mercurio (2013) defines 'assessment literacy' as teachers' capacity to deeply understand and reflect on their assessment practices in theoretical and practical contexts. Gallagher and Turley (2012) see 'assessment literacy' as teachers' deep understanding of why they assess, when they assess and how they assess in ways that positively impact student learning whereas Wang et al. (2008) indicate that a key feature of assessment literacy is understanding which assessment methods to use to gather dependable information about student achievement.

According to Stiggins (1995: 238), teachers ought to understand that assessment is a key to success in learning, and that school improvement efforts will not be productive unless and until educators become masters of the basic principles of sound classroom assessment practices. Sound classroom assessment practices do not focus on finding 'ever more sophisticated and efficient ways of generating valid and reliable test scores' so that learners are pressurised to conform to the norms of the metric dictated by the bureaucracy (Stiggins, 2002: 759); on the contrary, it acknowledges and accommodates the complexity of the learner in implementing alternative types, methods, techniques and tools of assessment to enhance deep and meaningful learning which will benefit the learner in future. Boud (2000: 151) states that an assessment act should ideally contribute in some way to learning beyond the 
immediate task by meeting the needs of the present and preparing students to meet their own future needs. Stobart (2010) calls this sustainable assessment, since it equips learners for lifelong learning in the unknown future of the $21^{\text {st }}$ century. He warns that assessment 'snapshots', i.e. simply assessing for the here and now (as currently seems to be the case with the series of formal SBA tasks prescribed by CAPS), is insufficient if nothing substantial and useful such as 'learning to learn' and critical thinking are carried forward.

Teachers need to ask themselves what their learners will be able to take into their unknown futures from the assessment practices that are currently shaping their identities as learners, and then act on the responsibility to provide rich opportunities for developing more flexible and active forms of learning. According to Stobart (2010:9) teachers are in the excellent position to do so because they know what has been taught, though not necessarily what has been learnt, and can therefore devise 'less predictable' questions on higher cognitive levels to assess how well their learners are able to use new knowledge and skills in unfamiliar forms or contexts. In this way the teacher will not only assess 'principled' knowledge (which can be transferred to new situations) but will also get feedback on misconceptions that would not necessarily be revealed by more predictable 'recall' answers. Teachers are thus challenged to generate authentic assessment tasks (within the framework suggested by the CAPS) that foster the development of learners' cognitive skills instead of continually mimicking external examinations (DBE, 2014: 122).

\section{Focusing on LOA in language teaching and learning}

The term LOA has been selected in this discussion on EFAL assessment because the SBA programme in CAPS is made up of a series of summative classroom tasks, tests and examinations. LOA views tests and examinations in Second Language (L2) ${ }^{1}$ studies as integral parts of assessment for learning because it believes with good coherence between classroom teaching and what is being tested, tests and examinations can have a positive impact by providing evidence both of what learners have learned and what they can do. As mentioned earlier, teachers play an important role in creating an environment productive of learning. That includes embedding all planned and unplanned assessments within teaching and learning contexts and using assessment evidence to evaluate learning goals and advance high level EFAL learning objectives to the benefit of each individual and of the group as a whole.

Purpura (2014) explains that LOA is an approach to assessment that prioritises the centrality of L2 processing and L2 learning outcomes, resulting from planned and unplanned assessments, in a variety of learning and assessment contexts. Learning an L2 in whatever context is seen as an individual cognitive process (an effective way of assessing what the individual has learned is one-on-one tests and examinations) but when situated within collaborative learning and assessment spaces, it also involves a layered set of socio-cognitive and sociocultural processes (Purpura, 2014). The outcome of these processes may be more effectively assessed by using a variety of speaking and writing tasks.

The applicability of LOA as an assessment approach in EFAL finally lies in the fact that it recognises the symbiotic relationship among external standards, curriculum, instruction, learning, and assessment, and is concerned with the role that these synergies play in

\footnotetext{
${ }^{1}$ The term EFAL is preferred in South Africa

Per Linguam 2016 32(2):1-14

http://dx.doi.org/10.5785/32-2-624
} 
understanding learner performance, engagement, learning processes, and the attainment of learning success (Purpura, 2014).

A weakness in the CAPS for EFAL in terms of assessment is the fact that a clear distinction is drawn between informal or daily assessment which is seen as assessment for learning, and formal assessment which is seen as assessment of learning (DBE, 2011: 77). CAPS explains that informal or daily assessment serves the purpose of continuously collecting information on a learner's achievement that can be used to improve learning. On the other hand, formal assessment tasks, including SBA tasks, are to be marked and formally recorded by the teacher for progression and certification purposes.

The CAPS perception of formative and summative assessment is typical of an examinationdominated culture. In such a culture, formative and summative assessment are seen as distinctly different in both form and function, and teacher and assessor roles are clearly demarcated, while in SBA summative assessments are meant to be used formatively in giving constructive feedback and improving learning (Cheng, Andrews \& Yu, 2010: 222).

\section{Aligning teaching, learning, and assessment with curriculum aims and objectives}

A starting point for EFAL teachers in the FET phase would be to carefully consider the role of assessment in the process of attaining the aims and objectives expressed in the CAPS for EFAL in the FET phase. CAPS states that the National Curriculum Statement Grades R-12 (among other objectives) aims to produce learners that are able to:

- identify and solve problems;

- think critically and creatively;

- work effectively as individuals and in groups;

- organise and manage themselves and their activities responsibly and effectively;

- collect, analyse, organise and critically evaluate information;

- communicate effectively using visual, symbolic and/or language skills in various modes; and

- use science and technology effectively

(DBE, 2011: 5).

Furthermore, learning EFAL should enable learners to:

- acquire the language skills necessary to communicate accurately and appropriately taking into account audience, purpose and context;

- listen, speak, read/view and write/present the language with confidence and enjoyment.

- express and justify, orally and in writing, their own ideas, views and emotions confidently;

- use their Additional Language as a means of critical and creative thinking

(DBE, 2011: 9).

The coherence between these aims and objectives and classroom practice may be weakened by time constraints, an examination-driven system, and SBA restrictions but CAPS does allow teachers some latitude, within subject specifications, to develop quality learning and assessment programmes. The challenge is to link assessments to the curriculum and to 
integrate assessment into the instructional process to promote high level cognitive and affective learner development.

\section{Focusing on high level cognitive and affective development}

Shallow content coverage, as is typically found in examination drilling, never moves beyond the lower cognitive levels of remembering and understanding whereas SBA activities (as recommended by the Ministerial Task Team) should demand higher order thinking (DBE, 2014: 73).

The demand for higher order thinking aligns with educational demands in countries that perform exceptionally in international assessments. Darling-Hammond and McCloskey (2008: 264) note that the focus on $21^{\text {st }}$ century skills is what drove improvements in student learning in high performing European and Asian countries. These skills include the abilities to find and organise information to solve problems, frame and conduct investigations, analyse and synthesise data, apply learning to new situations, self-monitor and improve one's own learning and performance, communicate well in multiple forms, work in teams, and learn independently.

Astin and Antonio (2012: 273-274) lend another dimension to learner development. They believe that teachers should not exclusively emphasise the cognitive outcomes in education but also be more directly involved with the development of beliefs and values that will heal divisions among people and help create a society that is less materialistic, competitive, and selfish and more generous and cooperative. Assessment criteria for learning tasks should therefore also focus on the affective outcomes that need to be developed during the teenage years such as the ability to work in a group and participate in a meaningful way; respecting peers, and valuing ideas expressed by others. These outcomes are addressed in CAPS which states that the National Curriculum Statement (NCS) Grades R-12 serves the purpose of 'equipping learners, irrespective of their socio-economic background, race, gender, physical ability or intellectual ability, with the knowledge, skills and values necessary for selffulfilment, and meaningful participation in society as citizens of a free country'. The NCS is based on the principles of

- social transformation: ensuring that educational imbalances of the past are redressed and that learners get equal educational opportunities;

- active and critical learning: encouraging an active and critical approach to learning, rather than rote and uncritical learning of given truths;

- high knowledge and high skills;

- progression;

- human rights, inclusivity, environmental and social justice;

- valuing indigenous knowledge systems;

- credibility, quality and efficiency: providing an education that is comparable in quality, breadth and depth to those of other countries (DBE, 2011: 4-5).

The EFAL classroom should be seen as an ideal place to promote these principles since it is the largest single Grade 12 subject with close to $70 \%$ of all Grade 12 students writing the exam in 2015. 


\section{CONCLUSION}

Aligned with the international paradigm shift from AoL to AfL at the end of the previous millennium, SBA was incorporated as a component of the high-stakes NSC examinations in South Africa in 2000. Conceptually SBA is supposed to drive learning, feeding and fattening the cow, not examination results, weighing the cow. Yet, after nearly two decades SBA in EFAL is strictly aligned with preparation for end-of-year examinations in the FET band, and particularly with national testing that reduces the curriculum to basic linguistic knowledge and skills. High-performing European, Asian and Scandinavian nations, on the other hand, focus on how SBA in language learning may be used to prepare their learners to lead meaningful and successful lives in a global society in the $21^{\text {st }}$ century. Significantly greater cognitive and affective demands are being made on people in this century which means that teachers of EFAL in South African secondary schools, who are the primary agents of change and success in the classroom, need to focus on aligning teaching, learning, and assessment with high-level linguistic knowledge and skills. The challenge lies in cleverly using the latitude within the specifications of CAPS to devise meaningful learning and sustainable assessment programmes in the quest of finding a balance between assessment for learning and assessment in preparation of high stakes examinations. In the same breath, the South African Department of Education has the responsibility to intensively invest in teacher education and professional development in enhancing assessment literacy and then to effectively support teachers in the implementation of SBA while working towards finding a balance between trusting the professional judgement of the teacher and ensuring the validity and reliability of SBA results.

\section{REFERENCES}

ASSESSMENT REFORM GROUP. 2002. Assessing for learning: 10 principles. Port Melbourne: Cambridge University Press.

ASTIN, AW \& AL ANTONIO. 2012. Assessment for excellence. The philosophy and practice of assessment in higher education. $2^{\text {nd }}$ edition. Lanham: Rowman \& Littlefield.

BLACK, P, C HARRISON, C LEE, B MARSHALL \& D WILIAM. 2003. Assessment for learning: putting it into practice. Berkshire, UK: Open University Press.

BLACK, P \& D WILIAM. 1998. Inside the black box: Raising standards through classroom assessment. London: Granada Learning.

BOUD, D. 2000. Sustainable Assessment: Rethinking Assessment for the Learning Society. Studies in Continuing Education, 22: 151-167.

BRINDLEY, G. 1998. Outcomes-based assessment and reporting in language learning programmes: A review of the issues. Language Testing, 15: 45-85.

BROOKHART, SM. 2007. Expanding views about formative classroom assessment: a review of the literature. In McMillan, J.H (Ed), Formative classroom assessment: Theory into practice. New York: Teachers College Press. 43-63.

CAMBRIDGE ENGLISH LANGUAGE ASSESSMENT. 2016. Learning Oriented Assessment. Available from http://www.cambridgeenglish.org/research-andalidation/fitness-for-purpose/loa/ [Accessed: 12 March 2016].

CARLESS, D. 2007. Learning-oriented assessment: conceptual bases and practical implications. Innovations in Education and Teaching International, 44(1):57-66.

CARLESS, D, G JOUGHIN \& M. MOK. 2006. Learning-oriented assessment: principles and practice. Assessment and Evaluation in Higher Education, 31(4):395-398. 
CHENG, L, S ANDREWS \& Y YU. 2010. Impact and consequences of school-based assessment (SBA): Students' and parents' views of SBA in Hong Kong. Language Testing, 28(2):221-249.

DARLING-HAMMOND, L. \& L MCCLOSKEY. 2008. Assessment for learning around the world. What would it mean to be internationally competitive? Phi Delta Kappa, 90(4):263-272.

DAVISON, C. 2007. Views from the chalkface: English Language School-Based Assessment in Hong Kong. Language assessment quarterly, 4(1): 37-68.

DEPARTMENT OF BASIC EDUCATION. 2011. National Curriculum Statement. Curriculum and Assessment Policy Statement English First Additional Language Further Education and Training Phase Grades 10-12. Pretoria: Government Printing Works.

DEPARTMENT OF BASIC EDUCATION. 2012. National Protocol for Assessment Grades $R$-12. Pretoria: Government Printing Works.

DEPARTMENT OF BASIC EDUCATION. 2014. The Ministerial Task Team Report on the National Senior Certificate (NSC) 26 May. Pretoria: Government Printing Works.

DU PLESSIS, C. 2014. Issues of validity and generalizability in the Grade 12 English Home Language examination. Per Linguam, 30(2):1-19.

EARL, LM. 2013. Assessment as learning: using classroom assessment to maximise student learning. London: Sage.

GALLAGHER, CW \& ED TURLEY. 2012. Our better judgment: Teacher leadership for writing assessment. National Council of Teachers of English.

GOOD, R. 2011. Formative use of assessment information: it's a process, so let's say what we mean. Practical assessment, Research and Evaluation, 16(3):1-6.

HAMP-LYONS, L. 2012. HKDSE English Language Examination. Introduction to the School-based Assessment Component. Available from http://www.hkeaa.edu.hk/DocLibrary/SBA/HKDSE/Eng_DVD/sba_practice.html [Accessed: 9 March 2016].

HARLEN, W. 2012. On the relationship between assessment for formative and summative purposes. In Gardner, J.N (Ed), Assessment and learning. London: Sage. 87-102.

HERITAGE, M. 2013. Formative assessment in practice: a process of inquiry and action. Cambridge, M.A.: Harvard Education Press.

ISAACS, T, C ZARA, G HERBERT, SJ COOMBS \& C SMITH. 2013. Key concepts in educational assessment. London: Sage.

KAPP, R \& M AREND. 2011. 'There's a hippo on my stoep': Constructions of English Second Language teaching and learners in the new National Senior Certificate. Per Linguam, 27(1):1-10

KELlAGHAN, T \& V GREANEY. 2003. Monitoring Performance: Assessment and Examinations in Africa. Association for the Development of Education in Africa ADEA Biennial Meeting (Grand Baie, Mauritius, December 3-6, 2003). Available from http://toolkit.ineesite.org/toolkit/INEEcms/uploads/1089/Monitoring_Performance_Ass essment_Examinations.pdf [Accessed: 7 March 2016].

KOHN, A. 2001. Fighting the tests: a practical guide to rescuing our school. Phi Delta Kappan, 82(5):348-357.

LONG, C. 2006. Realising the potential of school-based assessment. Available from http://www.iaea.info/documents/paper_1162a1e406.pdf [Accessed: 10 March 2016].

MAK, P \& I LEE. 2014. Implementing assessment for learning in L2 writing: An activity theory perspective. System, 47:73-87. 
MCCOLLOW, J. 2006. Square pegs, round holes: defending school-based assessment. Professional Magazine. Available from http://www.qtu.asn.au/files/2413/2268/2363/vol21_mccollow.pdf [Accessed: 17 March 2016].

MERCURIO, A. 2013. Assessment and learning: building teachers' assessment literacy. (Paper presented at the $39^{\text {th }}$ Annual Conference of the International Association of Educational Assessment, Tel Aviv, Israel. 20-25 October). Available from http://www.iaea.info/documents/paper_5bc1b798.pdf [Accessed: 3 October 2014].

NEWTON, PE. 2007. Clarifying the purposes of educational assessment. Assessment in Education: Principles, Policy and Practice, 14(2):149-170.

PURPURA, JE. 2014. Teacher College Columbia University Roundtable in Second Language Studies (TCCRIS). Available from http://www.tc.columbia.edu/tccrisls/index.asp?Id=What+is+LOA\%3F\&Info=What+is + LOA\%3F. [Accessed: 9 March 2016].

QIAN, DD. 2010. Implementing school-based assessment in Hong Kong: Government policy and stake-holders' perceptions. In Lü, ZS, WX Zhang \& P Adams (Eds), ELT at tertiary level in Asian contexts: Issues and research. Hong Kong: The Hong Kong Polytechnic University. 108-119.

QIAN, DD. 2014. School-based English language assessment as a high-stakes examination component in Hong Kong: insights of frontline assessors. Assessment in Education: Principles, Policy \& Practice, 21(3): 251-270.

REA-DICKINS, P. 2006. Currents and eddies in the discourse of assessment: a learningfocused interpretation. International Journal of Applied Linguistics, 16(2):163-188.

REYNEKE, EM, LW MEYER \& C NEL. 2010 School-based assessment: the leash needed to keep the poetic 'unruly pack of hounds' effectively in the hunt for learning outcomes. South African Journal of Education, 30(2):277-292.

SHEPARD, LA. 2007. Formative assessment: Caveat emptor. In Dwyer, C.A. (Ed), The future of assessment: Shaping teaching and learning. Mahwah, NJ: Lawrence Erlbaum Associates. 279-309.

STANLEY, G, R MACCANN, J GARDNER, L REYNOLDS \& I WILD. 2009. Review of teacher assessment: Evidence of what works best and issues for development. Oxford: Oxford University Centre for Educational Assessment.

STIGGINS, RJ. 1995. Assessment literacy for the 21st century. Phi Delta Kappan, 77(3): 238-245.

STIGGINS, RJ. 2002. Assessment Crises: The absence of assessment for learning. Phi Delta Kappan, 60(3):758-763.

STOBART, G. 2010. Assessment fit-for-the-future. (Paper presented at the $36^{\text {th }}$ Annual Conference of the International Association of Educational Assessment, Bangkok, $\begin{array}{llll}\text { Thailand } & \text { 20-27 August). } & \text { Available }\end{array}$ http://www.iaea.info/documents/paper_4d520c71pdf [Accessed: 10 April 2016].

TICAL, 2009. Position paper on assessment for learning from the Third International Conference on Assessment for Learning. 15-21 March, Dunedin, New Zealand. Available from http://www.fairtest.org/position-paper-assessment-learning [Accessed: 7 March 2016].

VLACHOU, MA. 2015. Does assessment for learning work to promote student learning? The England paradigm. The Clearing House 88:101-107.

WANG, TH, KH WANG \& SC HUANG. 2008. 'Designing a web-based assessment environment for improving pre-service teacher assessment literacy'. Computers \& Education, 51(1):448-462. 
WILIAM, D. 2011. Embedded formative assessment. Bloomington, IN: Solution Tree Press.

\section{BIOGRAPHICAL NOTE}

Maryna Reyneke is a senior lecturer in English for Education at the Faculty of Education Sciences at the North-West University in Potchefstroom. Her fields of interest are English Language Teaching, English Medium of Instruction, and Assessment.

Email: Maryna.Reyneke@nwu.ac.za 